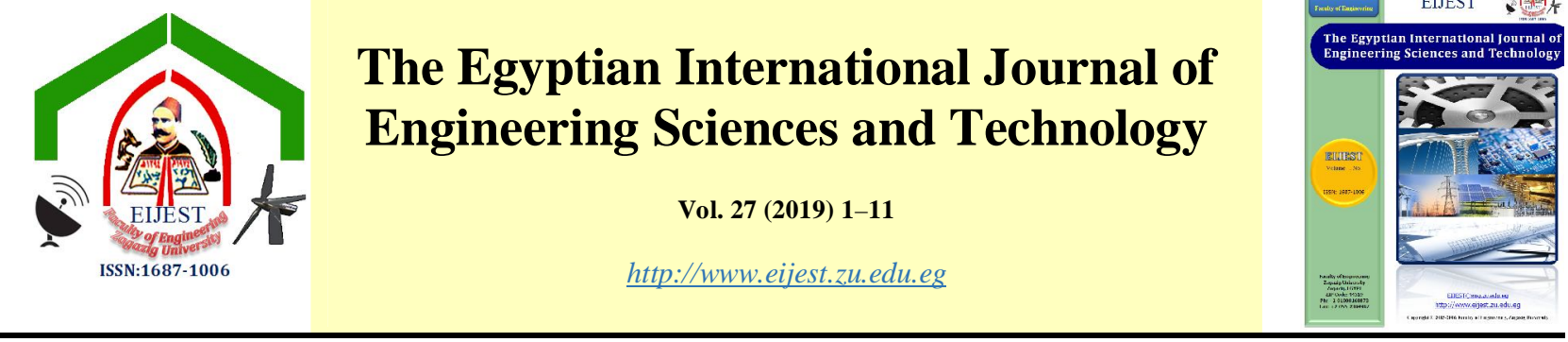

\title{
Evaluation the Existing Nile River Navigation Path in The Reach from Aswan City to Esna Barrage
}

\author{
Reham Elsayed $^{\mathrm{a}}$, AbdelazimNegm $^{\mathrm{b} *}$, Kamal Ali $^{\mathrm{c}}$ and Shenouda Ghaly ${ }^{\mathrm{d}}$ \\ ${ }^{a, c, d}$ Civil Engineering Dept., Aswan University, Aswan, 81542, Egypt \\ ${ }^{b^{*}}$ Water and Water Engineering Dept., Zagazig University, Zagazig, 44519, Egypt
}

\begin{tabular}{l}
\hline A R T I C L E I N F O \\
\hline Article history: \\
Received24November 2018 \\
Received in revised form \\
24December 2018 \\
Accepted 30 December 2018 \\
Available online 00 January \\
2019 \\
\hline
\end{tabular}

\section{Keywords:}

River Navigation;

Morphological Changes;

ArcGIS;

HEC-RAS,

HEC-GeoRAS

\section{Introduction}

Rivers and channels are completely dynamic systems, and they are subjected to significant changes in their position, shape, and morphological characteristics over time [1]. The changes in river beds morphology can be basically rendered because of the transaction mechanism transpired between bed and suspended sediments, which causes the deposition and erosion processes [2]. This in turn directly impede many river activities such as river navigation [3]. For instance, the Nile River is used as a transportation route connecting the South and North parts of Egypt. The navigation though the Nile River can reduce the pressure on land transportation in tourism and cargo activities. However, it is significant to maintain the minimum requirements for a safe day and night navigation path (channel width of $100 \mathrm{~m}$ and water depth of $2.3 \mathrm{~m}$ ), which were determined by River Transport Authority (RTA) and Nile Research Institute (NRI) [4,5]. Navigation study though water passes principally depends on evaluation changes of their morphology. Hence, studying the morphological changes through the Nile River is paramount to determine the optimum navigation path. Many studies of river morphology were carried out on the international levels based on field investigations and mathematical models [6-8]. However, Limited studies explored the navigation conditions though the second, third, and fourth reaches of the Nile River [5,9-11]. Nevertheless, no studies investigated these conditions in the first reach of the river Nile to the best of our knowledge. In addition, several 1D and 2D mathematical/hydraulic models were accomplished using SMS and CCHE2D for the bed of the Nile River [12-15]. However, limited researches have utilized HEC-RAS modelling. HEC-RAS (Hydraulic Engineering Center's - River Analysis System) is a well-known software used in hydraulic simulation, developed by US Army Corps of Engineer [16]. HEC-RAS also has taken advantage to be easily connected with GIS tools via HEC-GeoRAS that allows engineers to develop geometric data for import in HEC-RAS and view export water surface profile result data [17]. 


\section{Study Objectives}

The main objective of the current study is to evaluate the stability of the existing navigation path through the first reach of the Nile River using the combination between GIS and HEC-RAS modeling. This can be achieved by the following sub-objectives:

- Creating a map of changes between years 2011 and 2014 for the study area as an initial study to determine the erosion and sedimentation positions.

- Evaluating the GIS/HEC-RAS combination to create a morphodynamic study that the morphological changes in the study area that affect directly the navigation conditions through the first reach of the Nile River.

- Finally, evaluating the stability of the existing navigation path through the study area.

Notice, this study is not for detecting the navigation problems in the study area. Therefore, a part of the first reach of the Nile river was chosen to implement the current study (we don't know if it contains any navigation problems or not).

\section{Literature Review}

In this section, some examples of previous studies on the navigation problems through the Nile River and detecting the morphological changes of the Nile River Reaches using mathematical models:

- Sadek et al., (2008) [18] evaluated the future situation of the proposed navigational path through the fourth reach of the River Nile using GSTARS 2.0 modeling. They predicted the future changes occurred between 2006 and 2017 in the riverbed when $350 \mathrm{Mm} 3 /$ day as emergency discharge released. It was found that some cross sections along the study reach underwent navigational bottlenecks due to riverbed aggradation.

- Kamal et al., (2017) [9] developed Computerbased systems that aid users to evaluate the navigation efficiency and morphological changes at bottlenecks locations along the second reach of the Nile river. GIS application was also used to determine the navigation bottlenecks locations at years 1982 and 2016.
- Raslan et al., (2010) [19] investigated the changes in river morphology resulted from the construction of Sannour roadway culvert. HECRAS software was applied to estimate the flow characteristics and the efficiency of the roadway culvert.

- Sallam and Aziz (2003) [20] developed HECRAS Model to evaluate local scour around ElMinia Bridge piers between years 1982 and 2001. The mathematical simulation of the bridge local scour showed a local scour of a depth $4.90 \mathrm{~m}$ showing higher accuracy of the created model where difference between the measured scour and calculated scour about 6.5 $\%$.

- Another analysis of morphological changes around Aswan and El-Minia bridges was investigated by Moussa (2017) [21]. He evaluated the local scour during the period from 1982 to 2007 through 1-D and 2-D mathematical models using HEC-RAS and CCHE2D, respectively. The local scour and contraction scour at Aswan Bridge were higher than El-Minia Bridge due to the big dimensions of piers. 2D model gave accurate results particularly in the non-uniform cross sections.

\section{HEC-RAS Governing Equations}

HEC-RAS (Hydraulic Engineering Center's River Analysis System) is a well-known software used in hydraulic simulation, developed by US Army Corps of Engineer. HEC-RAS can perform both 1D and 2D computations, steady and unsteady state for river reaches. It also can do water quality computation and sediment transport simulation [16]. 1D unsteady flow routing solves the Saint-Venant equations. The Saint-Venant equations were developed from Conservation of Mass (1) and Conservation of Momentum (2) applied to a small control volume of fluid [16]. The HEC-RAS sediment routing routines solve the sediment continuity equation also known as the Exner equation (3) $[16,22]$. Like most continuity equations, the Exner equation simply states that the difference between sediment entering and leaving a control volume must be stored or removed from storage. The Exner equation translates the difference between inflowing and outflowing loads into bed change, eroding or depositing sediment [16]. HEC-RAS solves the sediment continuity equation by 
computing a sediment transport capacity for control volume (Qs-out) associated with each cross section, comparing it to the sediment supply (Qs-in) entering the control volume from the upstream control volume or local sources (e.g. lateral sediment loads)[16].

$\frac{\partial A_{T}}{\partial t}+\frac{\partial Q}{\partial x}-q_{l}=0$

$\frac{\partial Q}{\partial t}+\frac{\partial Q V}{\partial x}+\mathrm{gA}\left(\frac{\partial \mathrm{z}}{\partial x}+S_{f}\right)=0$

Where: $A=$ Area of cross sectional flow $\left(\mathrm{m}^{2}\right)$; $Q=$ Discharge $\left(\mathrm{m}^{3} / \mathrm{s}\right) ; q_{l}=$ Lateral inflow per unit length $\left(\mathrm{m}^{2} / \mathrm{s}\right) ; \quad \mathrm{V}=$ Velocity $(\mathrm{m} / \mathrm{s}) ; \frac{\partial z}{\partial x}=$ Water surface slope; $S_{f}=$ Friction slope

$\left(1-\lambda_{p}\right) B\left(\frac{\partial \eta}{\partial t}\right)=-\frac{\partial Q_{s}}{\partial x}$

Where: $B=$ channel width $\quad \eta=$ channel elevation $\lambda_{p}=$ active layer porosity $Q_{s}=$ transported sediment load

\section{Research Methodology}

\subsection{Location of the study area}

The study area with $10 \mathrm{~km}$ long reach of the first reach of the Nile River is located between cities Esna and Edfo (from km 135 to $\mathrm{km} 145$ downstream old Aswan dam). It is bound by $25^{\circ} 77^{\prime} 8.66 " \mathrm{~N}$ to $25^{\circ} 10^{\prime} 58.96 " \mathrm{~N}$ (see Fig.1). This part was chosen because all relevant hydraulic and bed sample material data are available. In addition, this study can be applied on any part of the first reach of the Nile River depending on the complete available data for those parts.

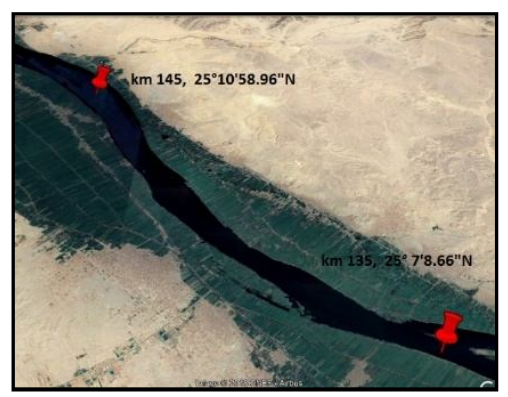

Fig.1 The study area between km 135 and km 145 downstream old Aswan Dam.

\subsection{Creating 3-D Model Using GIS}

To create a map that shows the changes occurred in the study area during the period from 2011 and
2014, a 3-D model was developed for the bed topography from the bathymetric maps made in years 2011 and 2014 (available from RTA) using ArcGIS 10.1. The Radial Basis Function (RBF) method was applied to give approximate values in areas that are not sampled directly in the study area [23]. The root mean square error (RMSE) for the study reach between the original and the predicted elevations using RBF method was calculated. The created map was exported to raster format, representing a more detailed 3D bed surfaces for the years 2011 and 2014. Finally, the 3D bed surfaces were used to produce the map of changes.

\subsection{HEC-RAS model}

Fig. 2 illustrates step-by-step the procedure followed to simulate the flow and sediment modeling using GIS and HEC-RAS model.

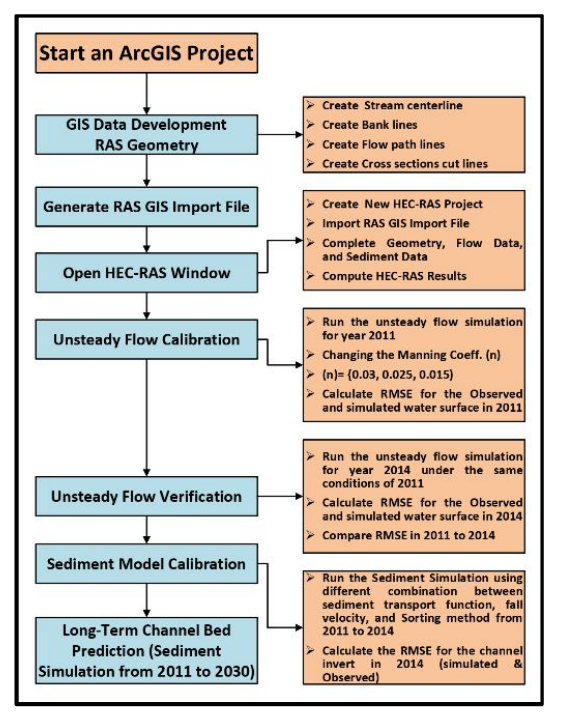

Fig. 2HEC-RAS Model Set-up[16]

\subsubsection{Adding geometric data}

HEC-GeoRAS was used to prepare the geometric data for HEC-RAS modeling in ArcMap. The layers that were created in this case were the stream centerlines, banks lines, flow paths, and cross section cut lines [16].

\subsubsection{Adding the flow data of the river to the model}

For the unsteady flow data, the boundary conditions were provided as following: the upstream boundary condition was set as the flow hydrograph of the year 2011. The downstream boundary condition 
was the rating curve for the same year at the $\mathrm{km} 145$. Regarding the sediment modelling, quasi-unsteady flow data were added to the model [16]. For this purpose, the upstream and downstream boundary conditions were set-up using the same data in case of unsteady flow but with some modification. In the upstream boundary, flow series were used, (Flow duration $=24 \mathrm{hrs}$, computational increment $=1 \mathrm{hr}$ ). In the downstream boundary, the same rating curve at $\mathrm{km} 145$ was used. All Flow data were available from RTA and Nile Research Institute (NRI).

\subsubsection{Adding sediment data to the model}

The bed sample material at cross-sections at $\mathrm{km}$ 135 and $\mathrm{km} 145$ downstream old Aswan Dam were used to define the bed gradation for each cross section. Bed sample materials were mainly sand formation, about $0.46 \%$ course sand, $63 \%$ medium sand, and $37 \%$ fine sand with average D50 of $0.22 \mathrm{~mm}$. All these data were obtained by RTA and NRI. Moreover, the maximum depth of the sediment control volume was taken $3 \mathrm{~m}$. Furthermore, the bank stations at each cross-sections were defined as the mobile bed and the width of erosion area [24]. Finally, the boundary conditions in this model was setup only at the upstream using Equilibrium Load boundary condition [16]. This method computes the boundary sediment load from the bed gradation and the transport capacity [16].

\section{Model calibration Procedure}

\subsection{Calibrating HEC-RAS hydraulic model}

For calibration, the water level calculated by the HEC-RAS model and the water level measured (Minimum \& Maximum) in 2011 was used. After trial and error, the manning coefficients were chosen in a way that the level difference in the simulated mode and current conditions was insignificant in the area [24,25] based on RMSE between observed and simulated stages.

\subsection{Calibrating HEC-RAS sediment model}

20 different combinations between sediment transport functions and fall velocity equations were examined to determine the best depositional equation overlapping with the natural conditions of the area $[24,25]$. Also, RMSE between the actual and simulated invert bed elevation was used in sediment model calibration step.

\section{Results and Discussion}

\subsection{3-D Model of Bed Morphological Changes Using GIS}

\subsubsection{3-D Model Accuracy Assessment}

The use of RBF interpolation method showed higher accuracy in years 2011 and 2014 as well. The RMSE was 0.089 and $0.087 \mathrm{~m}$ in years 2011 and 2014, respectively. These values are still less than 0.5 $\mathrm{m}$, which could be acceptable in our study. Finally, the new derived bed levels were used to create the 3D bed surface profiles in years 2011 and 2014 as shown in Figures started from Error! Reference source not found.a-d.

\subsubsection{Map of changes}

The changes in bed levels between the two predicted bed surfaces, shown in Error! Reference source not found., were generalized by three broad change categories, namely, no change, sedimentation and erosion. Map of changes for the period (from 2011-2014) was produced for the study area and presented in Error! Reference source not found. The results of statistics of the map of changes showed that the sediment amounts are about $1277800.41 \mathrm{~m}^{3}$, which concentrate in the middle part of the study area. Also, the erosion amounts are approximately equal to the sediment amounts, concentrating at the upstream and downstream parts. Finally, it could be concluded that the study area is exposed to sedimentation at the middle parts, but erosion occurs as the flow goes towards the downstream parts in more areas and amounts.

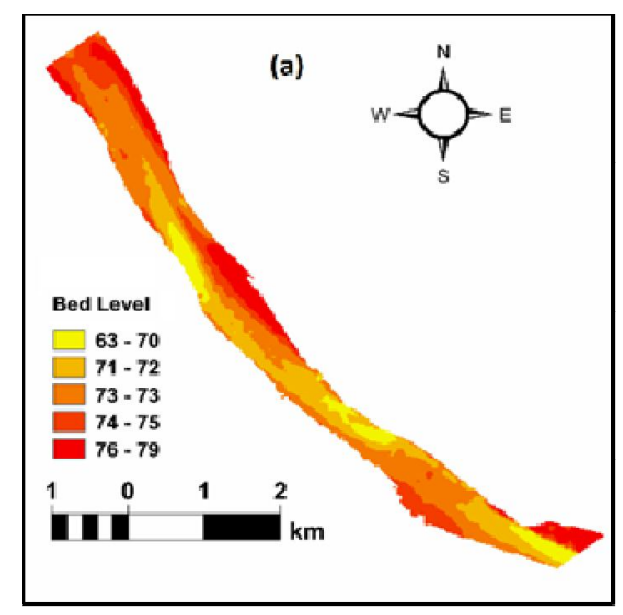



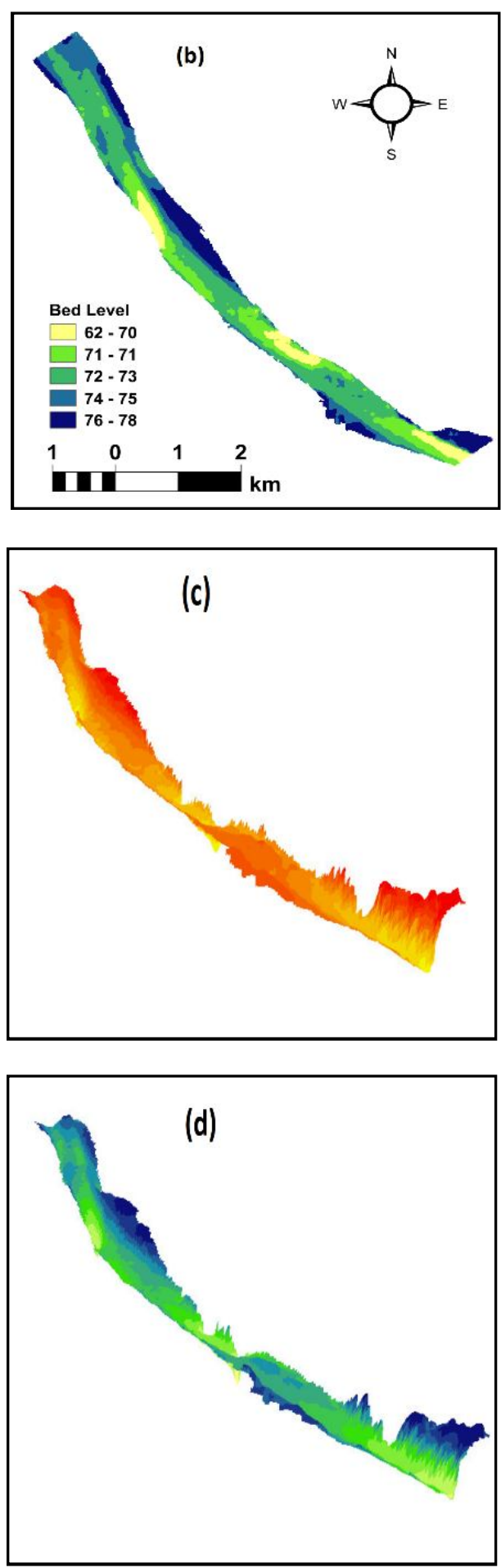

Fig.3 The Predicted Bed Levels of the study area in (a) 2011, (b) 2014; The Created 3-D Model of the Bed Surface of the Study Area in (c) 2011, (d) 2014.

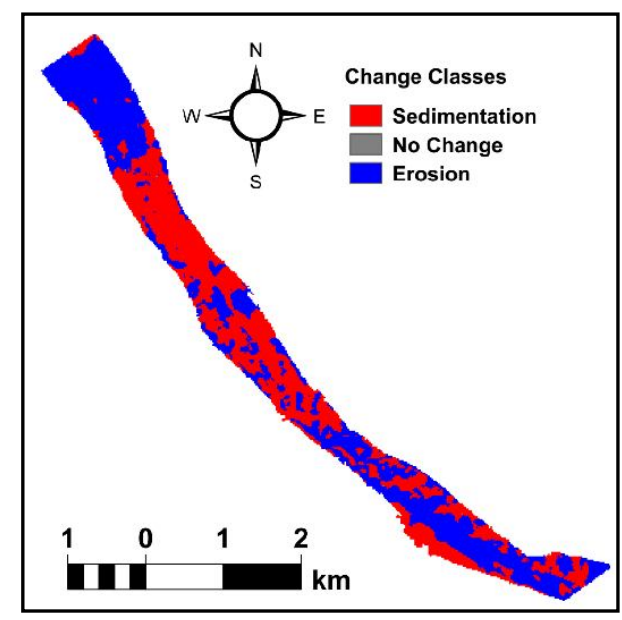

Fig.4 The Map of Change for the Study Area in the Period between 2011 and 2014.

\subsection{HEC-RAS Results}

\subsubsection{Hydraulic Model Calibration and Verification}

Several model runs were performed using different values of Manning coefficient to calibrate 1D unsteady HEC-RAS hydraulic model. The flow hydrograph during year 2011 was used as upstream boundary condition, and as a result the model calculated the water level. The results presented in Fig. 5 reveal great agreement between the two water levels at Manning coefficient of 0.025 and 0.015 for the banks and channel, respectively. RMSE error was also 0.11 and $0.14 \mathrm{~m}$ in case of maximum and minimum water levels, respectively indicating higher accuracy of calibration.

According to the calibration results, the model also was verified with respect to the maximum and minimum water level in 2014. To achieve this, the upstream boundary condition in 1-D unsteady HECRAS hydraulic model was the flow hydrograph from 2011 to 2014. The average flow hydrograph was used in years 2012 and 2013 to verify model (Run from 2011 to 2014). The respective verification results (

Fig.6) show significant agreement between the measured and calculated water surface elevations under the same conditions of the calibration results ( $\mathrm{n}$ $=0.025$ and 0.015 for the banks and channel, respectively). Also, the RMSE was calculated for this verification step, and it was 0.07 and $0.17 \mathrm{~m}$ in case of maximum and minimum water surface elevations, respectively. 


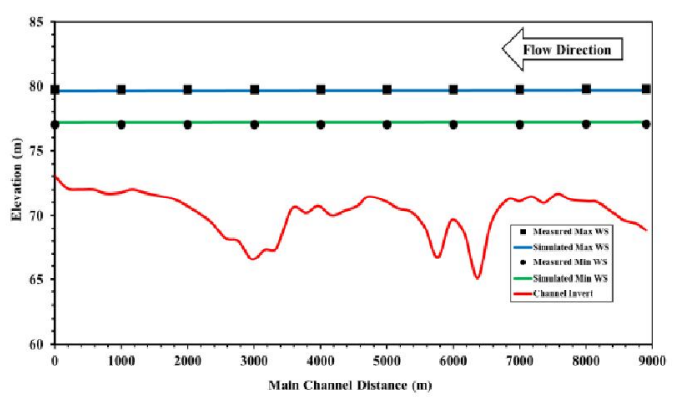

Fig.5 Comparison between the Measured and Simulated Water Surface Elevation in 2011.

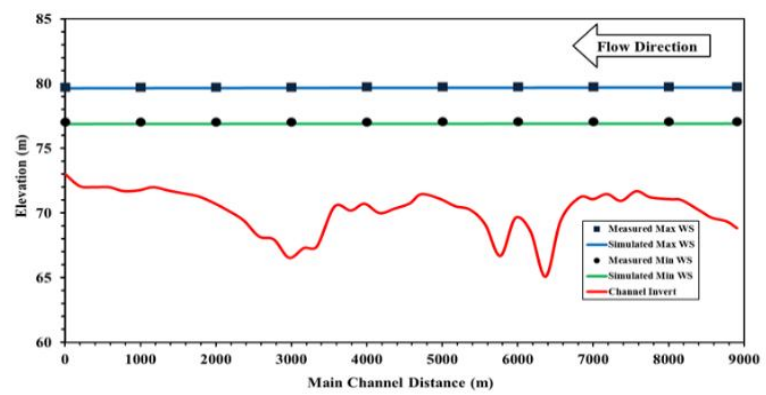

Fig.6 Comparison between the Measurement and Simulated Water Surface Elevation in 2014.

\subsubsection{Calibrating HEC-RAS Sediment Model}

To calibrate the sedimentation model, 20 different combinations of sediment transport and fall velocity equations were analysed in the software using quasiunsteady flow run in the period from 2011 to 2014. The results showed that among sediment transport and fall velocity equations, Toffaleti transport sediment equation and Toffaleti fall velocity method were the most consistent with the natural conditions of the study area. In addition, Fig.7 shows a comparison between the invert elevation of the study area in 2014, actual and model, which confirms that Toffaleti transport function was suitable for our case study where the RMSE of the invert point elevation was $0.53 \mathrm{~m}$. the sediment model finally calibrated to four cross-sections a, b, c, and d located along the study area (Fig.8). These cross-sections were chosen because they marked the max. erosion and sediment locations. Fig.9a-d compares between the actual and model cross-sections shape in year 2014, indicating great agreement stability in our model.

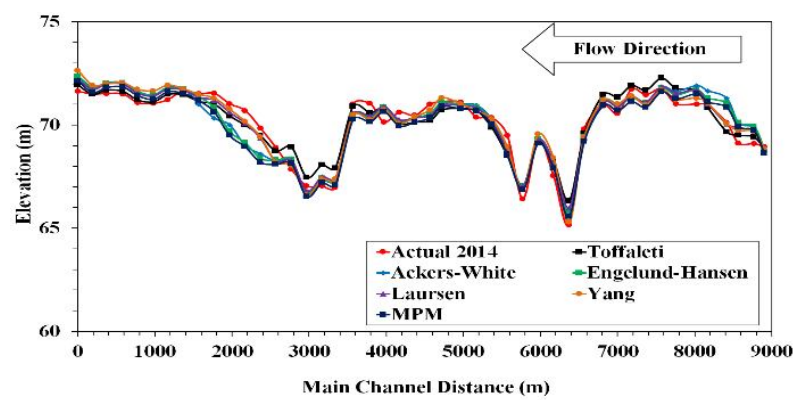

Fig.7 Compasion between The Invert Elevations of The Study Area in 2014, Actual and Simulated.

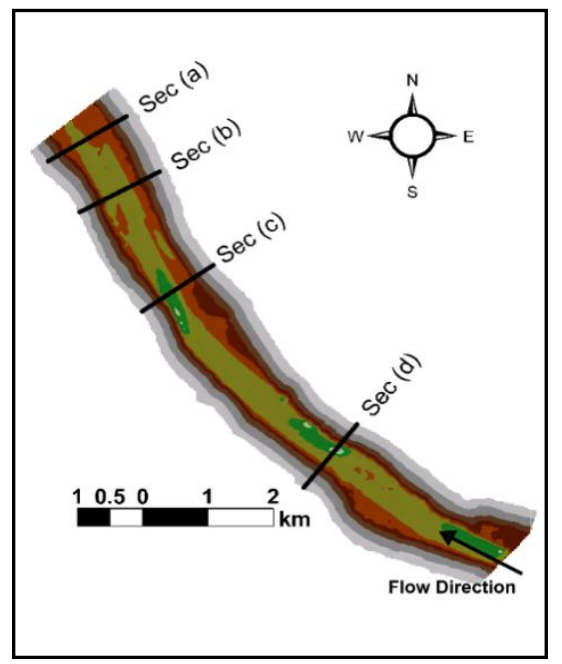

Fig.8 Location of The Cross-Sections Used for HEC-RAS Sediment Model Calibration.
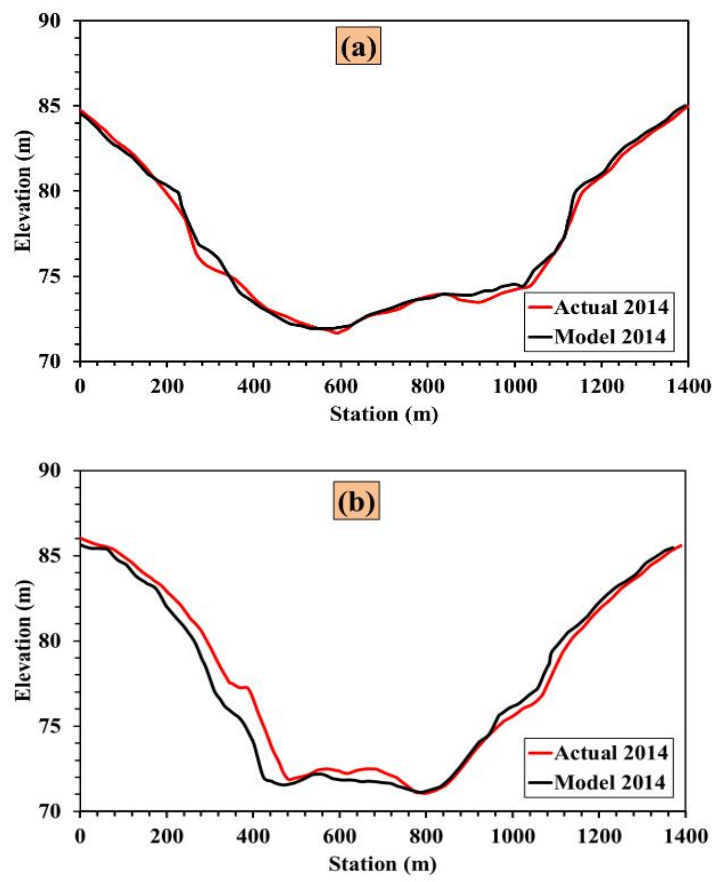

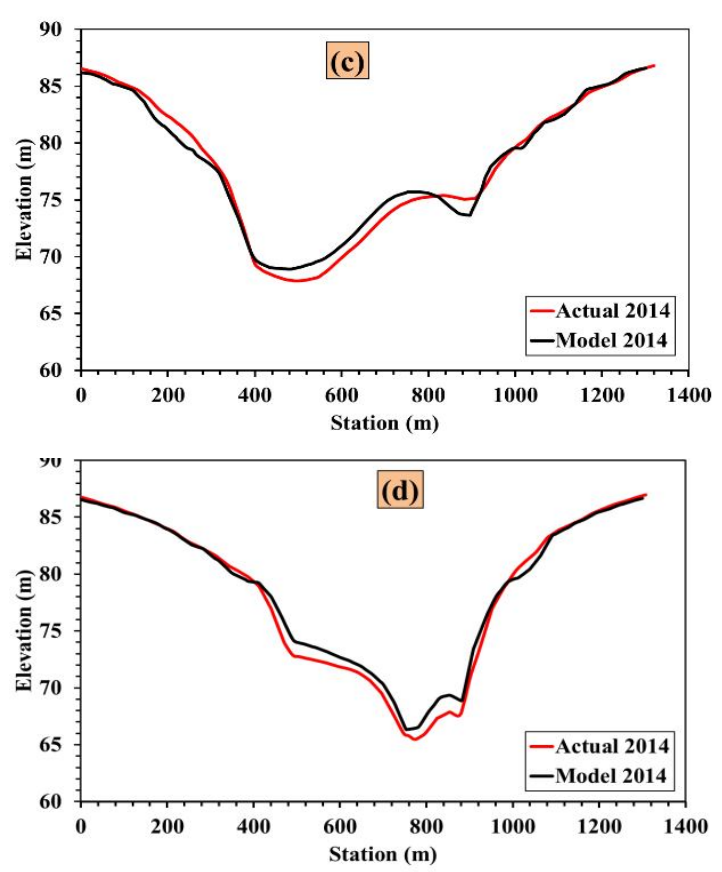

Fig.9 Comparison between The Actual and Simulated Cross-Sections in The Study Area.

\subsubsection{Sediment Transport Analysis Using HEC-RAS}

After calibration of flow and sediment, the model was used to predict the flow and sediment transport characteristics during 2011-2030 (20 years), and it was assumed that inflow of 2011-2014 would repeat for 20 years. The results showed in Fig. 10 reveal that the water level would decrease gradually every future 10 years by about $0.4 \mathrm{~m}$ at each cross-section. This could be attributed to the predicted sediment and erosion prosses that could happen in the sides of the study area.

This study also was extended to evaluate both the predicted velocity and shear stress distribution along the study length. The respective results illustrated in Fig. 11 show fluctuation between the initial velocity values (year 2011) and the predicted values in 2020 and 2030. In contrast, it is indicated a uniform regime between the predicted values in years 2020 and 2030 . Moreover, we could confirm that the velocity values would increase as long as the flow continuing moving towards the downstream. Finally, the shear stress variation in the above mention events of discharge across the study part in various sections is shown in Fig.12. The results give similar trends of the velocity distribution. In addition, it could present a relation between the two flow characteristics, in which around the positions of maximum velocities, maximum shear stress would be found. Where the highest value of shear stress is equal to $0.045 \mathrm{~Pa}$ in the section $2767.87 \mathrm{~m}$, the lowest value equals 0.017 $\mathrm{Pa}$ at station $5567.88 \mathrm{~m}$ in year 2030. For further illustration, the increase in velocity and shear stress along the study area could be attributed to the continuity equation and the applications of the specific energy theory(channel hump) [26,27]. The predicted sedimentation would decrease the water area at cross-sections exposed to sedimentation process. This is because the flow is assumed to be constant on every day during the study period. As a result, an increase in the flow velocity would be observed at sediment positions[26,27].

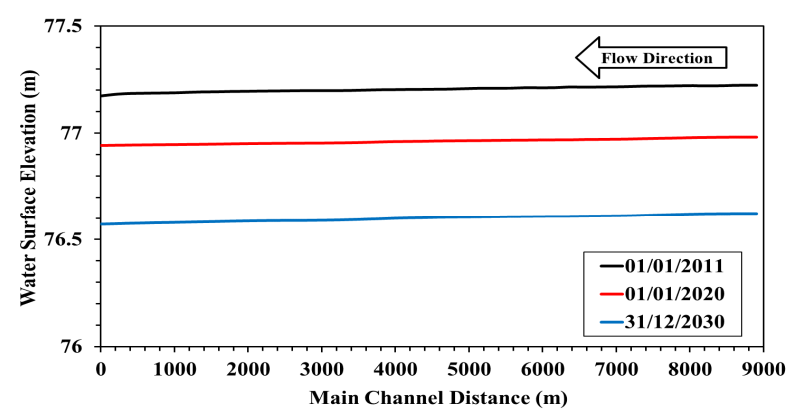

Fig.10 The Predicted Water Level Associated with the Sediment Analysis at Three Different Events (Quasi-Unsteady Flow Condition, Toffaleti Transport Function).

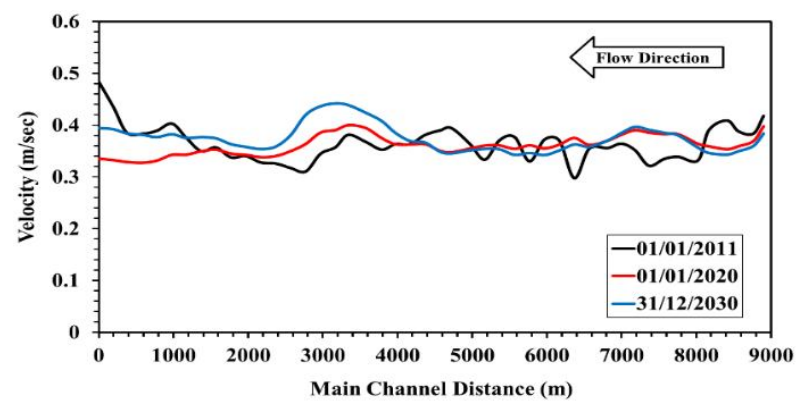

Fig.11 The Predicted Velocity Distribution Associated with the Sediment Analysis at Three Different Events (Quasi-Unsteady Flow Condition, Toffaleti Transport Function).

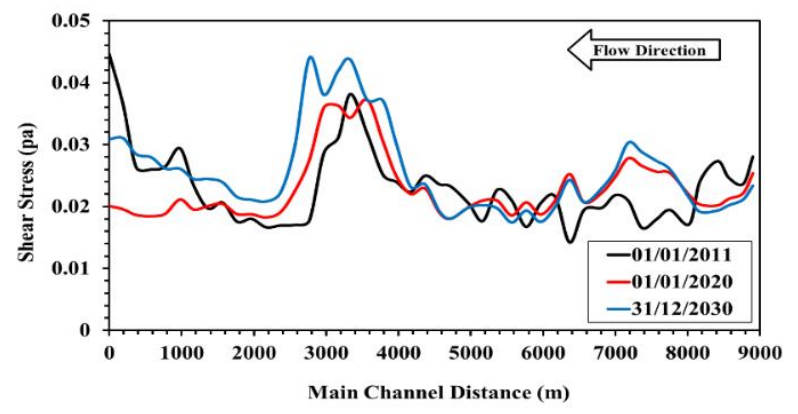

Fig.12 The Predicted Shear Stress Associated with the Sediment Analysis at Three Different Events (Quasi-Unsteady Flow Condition, Toffaleti Transport Function). 


\subsubsection{Long-Term Prediction of Channel Invert}

The RMSE of simulated bed elevation at (2020 and 2030) with initial ground elevation (2011) was used to estimate how much the riverbed were changed. RMSE values were 0.52 and $0.60 \mathrm{~m}$ in case of years 2020 and 2030, respectively. The longitudinal profile of our area of study in its initial position in 2011 and its predicted invert elevation in 2020 and 2030 is shown in Fig.13. It shows that significant changes would happen in its longitudinal profile in the future. Fig. 14 presents the predicted invert change in years 2020 and 2030. It shows that out of 46 sections, 14 sections would be eroded, and 31 sections would be deposited by the sediments in the presented event in 2020. This also matches with the expected decline in the water level (

Fig.10), according to the application of specific energy theory[26,27]. The study area exposed to higher amount of sediment with higher depth in 2020 and 2030 than erosion, which in turn could work as a channel hump resulting in the predicted water level reduction. The most sedimentation would take place in the stations $6367.88 \mathrm{~m}$ of the river and maximum erosion would occur in the sections zero, as shown in Fig.15a-b. Also, in case of simulation till 2030, about 10 districts would be erosion prone and 35 would be prone to sedimentation. For deep illustration, the maximum erosion depth would be observed in area (zero - 1167.36) at station zero with depth of 1.30 and $0.86 \mathrm{~m}$ in 2020 and 2030, respectively. This could be ascribed to the steep slopes $(\mathrm{S}=4.85 \mathrm{E}-06)$ in 2020 and $(\mathrm{S}=8.94 \mathrm{E}-06)$ in 2030. In contrast, the maximum sedimentation height in the area between $(5767.88-8024.51)$ at the section $6367.88 \mathrm{~m}$ was $1.67 \mathrm{~m}$ in both years 2020 and 2030 , which can be explained in terms of the slight slope of the river in this area $(\mathrm{S}=3.41 \mathrm{E}-06)$. Similarly, the area between stations (1167.36 4167.88, mean slope ( $\mathrm{S}=7.48 \mathrm{E}-06)$ ) would maintain higher sediment depth of 0.94 and $1.54 \mathrm{~m}$ at station $2767.87 \mathrm{~m}$ during the presented events in 2020 and 2030, respectively.

In HEC-RAS sediment model, mass bed change and invert change were used to interpret the sediment transport phenomenon on riverbed change along the study area. Mass bed change is a useful criterion to see trend. The predicted cumulative weight of the sediments in 2020 and 2030 is shown in Fig.16, which is in form of positive and negative values, where positive numbers show the weight of deposited sediments and negative numbers display the weight of transported or eroded sediments. The results confirm the same trend illustrated from the predicted invert change shown in Fig.14. The maximum mass of deposited sediment would be at the station 2767.87 $m$ in both 2020 and 2030 with values of 202404 and 285390.81 tons, respectively.

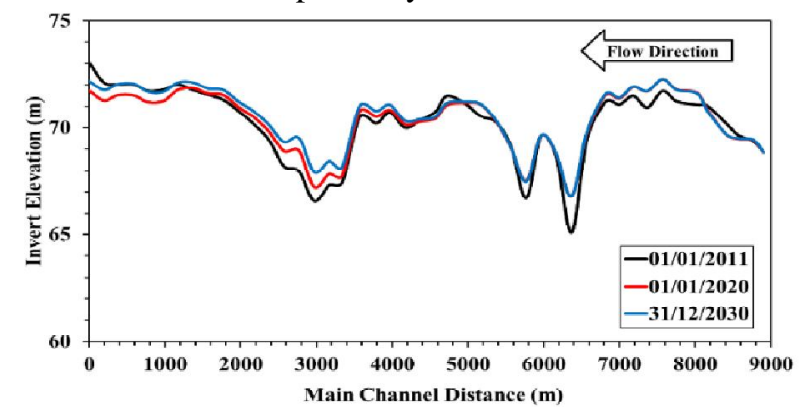

Fig.13 Comparison between The Initial Invert Elevation of The Study Area (2011) and The Predicted Invert Elevations (Quasi-Unsteady Flow Condition, Toffaleti Transport Function).

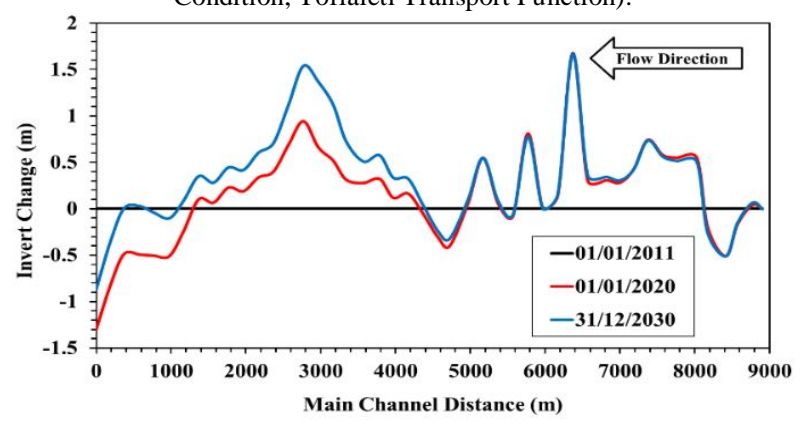

Fig.14 The Predicted Invert Change of The Study Area at 2020 and 2030 (Quasi-Unsteady Flow Condition, Toffaleti Transport Function)
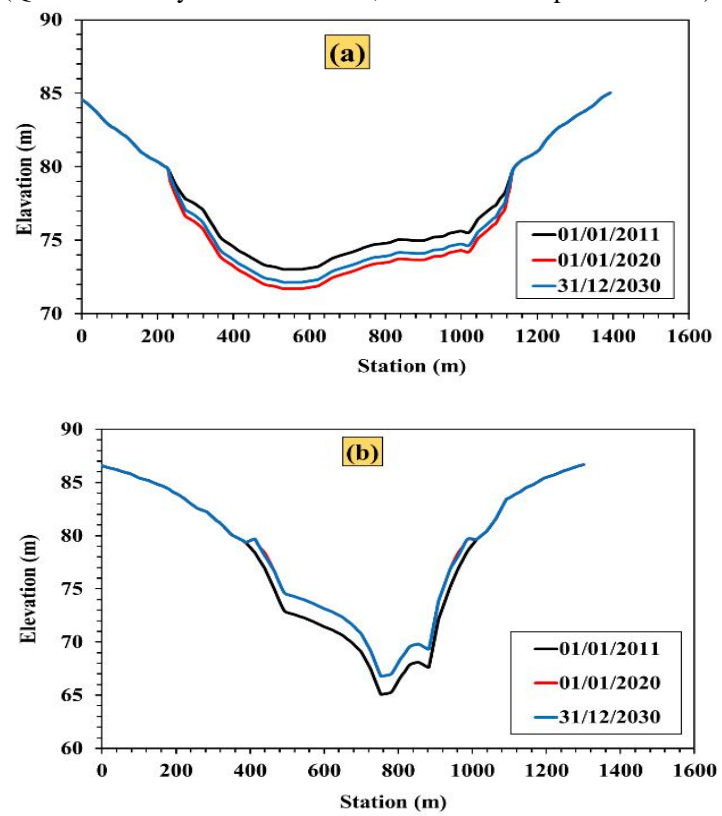

Fig.15 The Predicted Maximum Erosion and Sedimentation Positions in 2020 and 2030: (a) The Maximum Erosion at Station Zero m; (b) The Maximum Sedimentation at Stations $6367.88 \mathrm{~m}$ Respectively. 


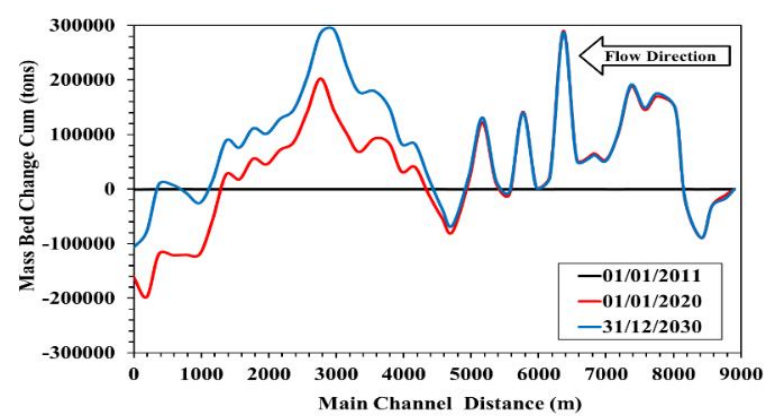

Fig.16 The Predicted Mass Bed Change Cumulative in tons.

\subsubsection{Evaluation the existing Nile River Navigation path}

The predicted navigation path at year 2030 is illustrated. After running sediment transport simulation till December 31, 2030, it was possible to predict the final riverbed elevation for the study area (Fig.17a). Firstly, River Transport Authority (RTA) determined the navigation path through the study area in year 2011 as shown in Fig. 17b. The determined navigation path passes though the lowest invert elevation points, where the bed elevation decreased gradually towards the west side in the middle of the study area continuing to the downstream. However, it almost passes though the centre of the study area starting from its upstream till the middle part. This can maintain the essential conditions for a better navigation path that Negm et. al., (2004) [10] mentioned. The exported results from the sediment transport simulation gave a prediction of overall sedimentation process occurring along the study area (Fig.14). For a safe navigation path, two fundamental conditions should be maintained, minimum path width of $100 \mathrm{~m}$ and minimum effective depth more than $2.3 \mathrm{~m}[4,5]$. In year 2030, no effective change in the channel width would occur, where the minimum channel width would be $450 \mathrm{~m}$. Regarding the effective water depth, measured from the invert riverbed to the water surface, Fig.18 shows a comparison between the observed water depth in 2011 and the predicted water depth in 2030 in the minimum water level events in winter season. For the current study area, it can be confirmed that water depth in 2011 covered the minimum effective depth required for a safe navigation path. This is based on that the minimum water depth in 2011 was about $3.25 \mathrm{~m}$ and the maximum value was about $8.80 \mathrm{~m}$. In case of 2030, the RMSE between the observed water depth in 2011 and the predicted in 2030 was calculated to approximately evaluate the variation that could happen. RMSE value was about $0.86 \mathrm{~m}$, showing that a decline in the effective water depth would transpire in 2030. Moving on to the navigation requirements, the effective water depth in 2030 would range between 3.4 to $7.1 \mathrm{~m}$. This water depth range reflects that even in 2030 it would cover the minimum water depth required for a safe navigation path in the study area. In brief, this reveals the validation of the existing navigation path introduced by RTA in 2011 till 2030 as well.
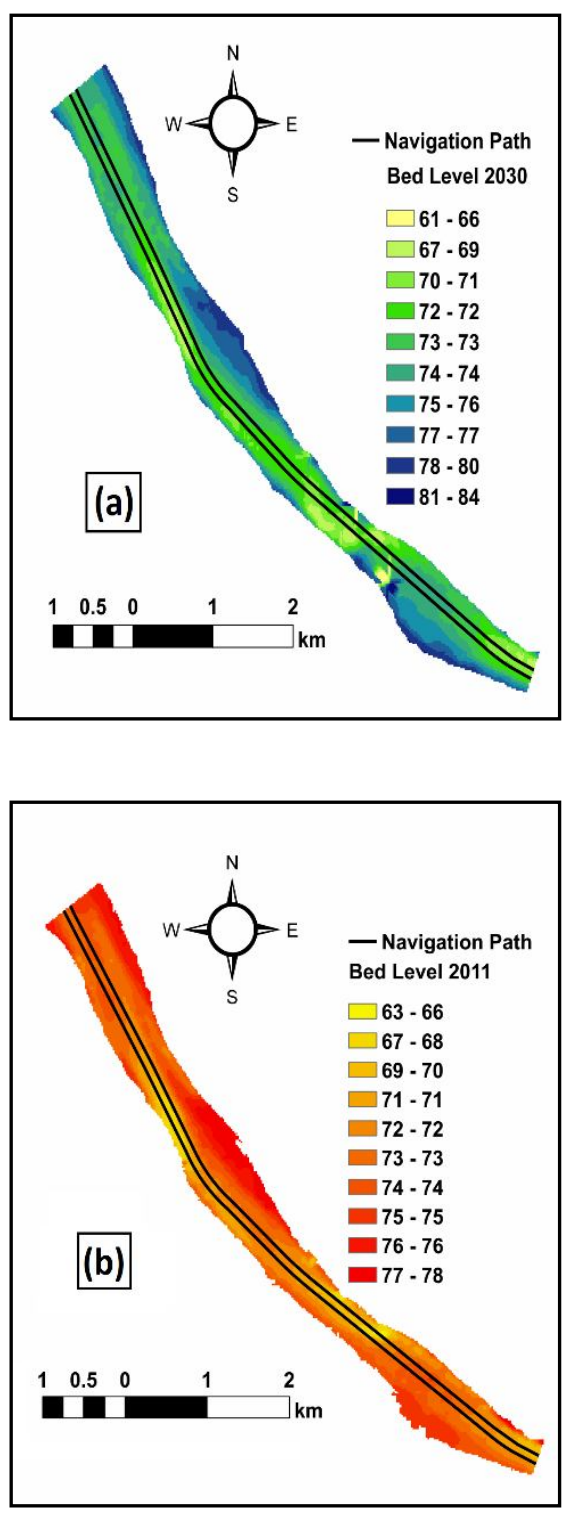

Fig.17 (a) The Predicted Bed Level of The Study Area in 2030 with The Navigation Path Provided by RTA in 2011; (b) The Bed Level in 2011 with The Navigation Path Provided by RTA in 2011. 


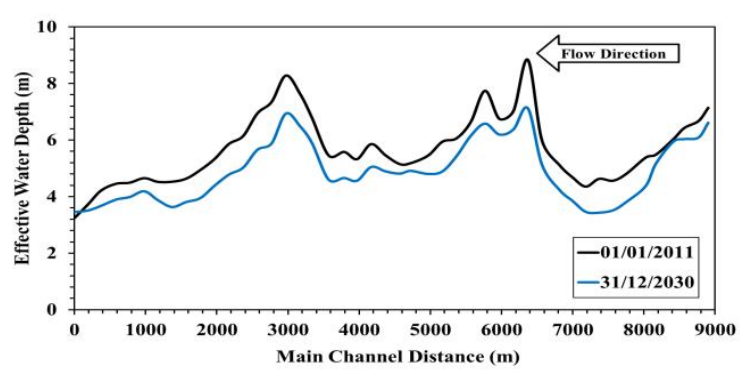

Fig.18 Comparison between The Observed Effective Water Depth in 2011 and The Predicted in 2030.

\section{Conclusions}

This work evaluated the existing Nile River Navigation path through the first reach of the Nile River (from $\mathrm{km} 135$ to $\mathrm{km} 145$ downstream old Aswan dam) depending on both GIS along with HEC-RAS modeling. The 3-D model resulted in driving map of changes that presented the position of sediment and erosion areas as well as their amounts between 2011 and 2014. Moreover, the study investigated a morphodynamic study for a part of the first reach of the Nile River of an area of $10 \mathrm{~km}$. The model was first calibrated for the flow and sediment, and then it was used for simulating flow sediment till 2020 and 2030. The results showed that the highest sedimentation would occur in the area between $(5767.88-8024.51)$ at the section $6367.88 \mathrm{~m}$ with $1.67 \mathrm{~m}$ depth in both years 2020 and 2030. After running sediment transport simulation till 2030, the final riverbed elevation for the study area was determined. In case of 2030, the RMSE showed that a decline in the effective water depth would transpire in 2030. Moving on to the navigation requirements, the effective water depth in 2030 would range between 3.4 to $7.1 \mathrm{~m}$. In brief, this reveals the validation of the presented navigation path introduced by RTA in 2011 till 2030 as well.

\section{Acknowledgments}

To all the faculty members of the Civil Engineering Department at Aswan University, specially Dr. Mohamed El-Sahabi and EngrSamehAraby. To Aswan University and Zagazig University.

\section{References}

[1] Das B, Sil BS. Assessment of Sedimentation in Barak River Reach Using HEC-RAS. Dev. Water Resour. India, vol. 75, 2017, p. 95-102. doi:10.1007/978-3-31955125-8.

[2] Sattar AMA. Bed Morphological Changes of the Nile River DS Major Barrages. Nile River. 1st ed., 2017, p. 171-86. doi:10.1007/698.

Ismail SS, Samuel MG. Response Of River Nile Dredging On Water Levels. Fifteenth Int. Water Technol. Conf. IWTC-15, Alexandria, Egypt: 2011, p. $1-17$.

[4] Abdel-aziz TM. Safe Visual Navigation on the Nile River. Sixth Int. Water Technol. Conf. IWTC, vol. 56, Alexandria, Egypt: 2017, p. 1-8. doi:10.13140/2.1.2107.6803.

[5] Raslan Y, Abdelbary M. Economical And Environmental Aspects Of Navigation Development In The Nile. Sixth Int. Water Technol. Conf. IWTC, Alexandria, Egypt: 2001, p. 319-28.

[6] Dutch Inland Shipping Information Agency (BVB). The power of inland navigation: The future of freight transport and inland navigation in Europe. Rotterdam: n.d.

[7] Solar MR. Inland Waterway Transport in the Rhine River: Searching for Adaption Turning Points. Wageningen University, 2012.

[8] BMVBS. Navigation and Waterways in Germany Meeting the Challenges of Climate Change. 2007.

[9] Kamal N, Sadek N. Evaluating and analyzing navigation efficiency for the River Nile ( Case study: Ensa-Naga Hamady reach ). Ain Shams Eng J 2017:1-21. doi:10.1016/j.asej.2017.08.006.

[10] Negm AM. Study Navigation Problems in Nile River Reach at Elbogdady. 2nd Int. Conf. Fluival Hydraul., Naples, Italy: Balkema; 2004.

[11] Sadek N, Salama R, Kamal N. Effect Of Bank Erosionand Bend Types On The Effciency Of Dammitta Branchnavigational Path. Int Water Technol Journal, IWTJ 2015;5:100-15.

[12] Moussa, A. M. A. Predicting the deposition in the Aswan High Dam Reservoir using a 2-D model. Ain Shams Eng J 2013;4:143-53. doi:10.1016/j.asej.2012.08.004.

[13] Moussa, A. M. A. Solving the problem of sedimentation at water intake of Rowd El-Farag pump station using 2D model Solving the problem of sedimentation at water intake of Rowd El-Farag pump station using 2D model. Ain Shams Eng J 2010:103-14. doi:10.1016/j.asej.2011.03.002.

[14] Nassar MA. Multi-parametric sensitivity analysis of CCHE2D for channel flow simulations in Nile River. J Hydro-Environment Res 2011;5:187-95. doi:10.1016/j.jher.2010.12.002.

[15] Negm AM, Abdel-aziz T, Nassar M, Fathy I. Estimating the Life Time Span of Aswan High Dam Reservoir Using Numerical Simulation of Nubia Lake. Nile River, 2017, p. 35-56. doi:10.1007/698. 
[16] Brunner W. G. HEC-RAS, River Analysis System Hydraulic Reference User's Manual version 5.0. 2016.

[17] Tate E, Maidment D. Floodplain Mapping Using HECRAS and ArcView GIS. 1999.

[18] Sadek N, Hekal N. Prediction of The Future Situation of The River Nile Navigational Path. Twelfth Int. Water Technol. Conf. IWTC12, 2008, p. 323-36.

[19] Raslan Y. Human Impacts on Nile River Morphology. Fourteenth Int. Water Technol. Conf. IWTC, 2010, p. 221-36.

[20] Sallam GA, Aziz M. A Study of Local Scour At Bridge Piers of El-Minia. Seventh Int. Water Technol. Conf. IWTC 2003 Egypt, 2003, p. 751-64.

[21] Moussa AMA. Evaluation of local scour around bridge piers for various geometrical shapes using mathematical models. Ain Shams Eng J 2017. doi:https://doi.org/10.1016/j.asej.2017.08.003.
[22] Paola C, Voller VR. A generalized Exner equation for sediment mass balance. J Geophys Res Earth Surf 2005;110:1-8. doi:10.1029/2004JF000274.

[23] Elsahabi M, Negm A. Building 3D Profile for Lake Nubia, Using RS/GIS for Accurate Estimation of Sediment. Procedia Eng., vol. 181, The Author(s); 2017, p. 845-52. doi:10.1016/j.proeng.2017.02.476.

[24] Motallebian M, Hassanpour F. A study of the locus of the erosion and sedimentation in Sistan River using HEC-RAS model. Int J Sci Eng Res 2013;4:1377-86.

[25] KIM Z. Assessment of Riverbed Change Due to The Operation of A Series Of Gates in A Natural River. Texas A\&M University, 2013.

[26] Subramanya K. Flow in Open Channels. Third Edit. New Delhi: Tata McGraw-Hill Publishing Company Limited; 2009.

[27] Moglen GE. Fundamentals of Open Channel Flow. Occoquan Laboratory, Virginia Tech: CRC Press; 2015. 